\title{
Xanthogranulomatous Osteomyelitis and Crohn's Disease: A Possible Association?
}

\author{
Catriona Scicluna ${ }^{a}$ Darko Babic ${ }^{b}$ Pierre Ellul $^{a}$ \\ ${ }^{a}$ Division of Gastroenterology, Department of Medicine, Mater Dei Hospital, Msida, Malta; \\ b Pathology Department, Mater Dei Hospital, Msida, Malta
}

Keywords

Xanthogranulomatous osteomyelitis · Crohn's disease .

Extraintestinal manifestation - Inflammatory bowel disease

\section{Osteomielite xantogranulomatosa e Doença de Crohn: uma associação possível?}

\section{Palavras Chave}

Osteomielite xantogranulomatosa - Doença de Crohn . Manifestação extra-intestinal · Doença inflamatória intestinal

A 20 -year-old male presented with a 10-week history of abdominal pain, bloody diarrhea, and right-sided pelvic pain. Initial blood investigations showed a $\mathrm{C}$-reactive protein level of $87 \mathrm{mg} / \mathrm{L}$ (normal $<10$ ). Other routine blood investigations were within normal limits. Stool samples for culture, ova, cysts, parasites, and Clostridium difficile were normal. At colonoscopy, there was patchy erythema with loss of vascular pattern and aphthous ulcers from the rectum to the caecum; the terminal ileum was normal. Biopsies were consistent with Crohn's dis-

\section{KARGER}

E-Mail karger@karger.com www.karger.com/pjg
(C) 2019 Sociedade Portuguesa de Gastrenterologia Published by S. Karger AG, Basel

Karger

Open access

This article is licensed under the Creative Commons AttributionNonCommercial-NoDerivatives 4.0 International License (CC BYNC-ND) (http://www.karger.com/Services/OpenAccessLicense). Usage and distribution for commercial purposes as well as any distribution of modified material requires written permission. ease (CD). The patient was treated with a tapering course of prednisolone and mesalazine, with resolution of the intestinal and pelvic symptoms. However, a few months later, the right-sided pelvic pain recurred. A computed tomographic enterography scan was performed, which showed a 21-mm lesion in the right pubic bone.

In view of persistent, severe, and disabling abdominal pelvic pain, a repeat computed tomographic enterography was performed 3 months later, with the only abnormality being that the bony lesion had increased in size to $62 \times 41 \times 36 \mathrm{~mm}$. This was centered around the right superior pubic ramus in a parasymphyseal location, with perforation affecting the superior pubic ramus. There was no sclerosis, extraosseous extension, or internal matrix mineralization. Pelvic magnetic resonance imaging (MRI) demonstrated low signal intensity on T1, heterogeneous signal intensity on STIR imaging, and avid enhancement with gadolinium (Fig. 1, 2). An isotope bone scan excluded other skeletal lesions. A computed tomography-guided biopsy showed a bone sample infiltrated by aggregates of histiocytes and foamy macrophages, including occasional giant cells and numerous plasma cells, with some rare cholesterol clefts. Some lymphocytes were seen in the background with no evidence of infection (Fig. 3, 4). This was consistent with xanthogranulomatous osteomyelitis (XO). Tissue culture did not yield any bacterial 


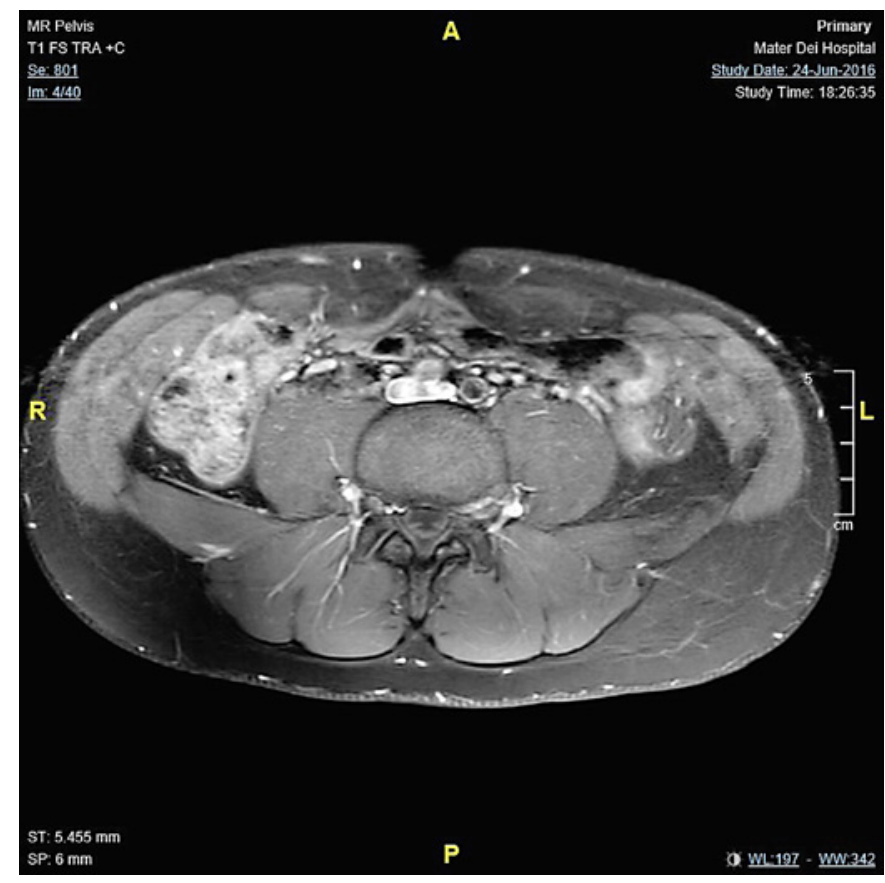

Fig. 1. Transverse T1-weighted MRI of the pelvis showing the right bone lesion.

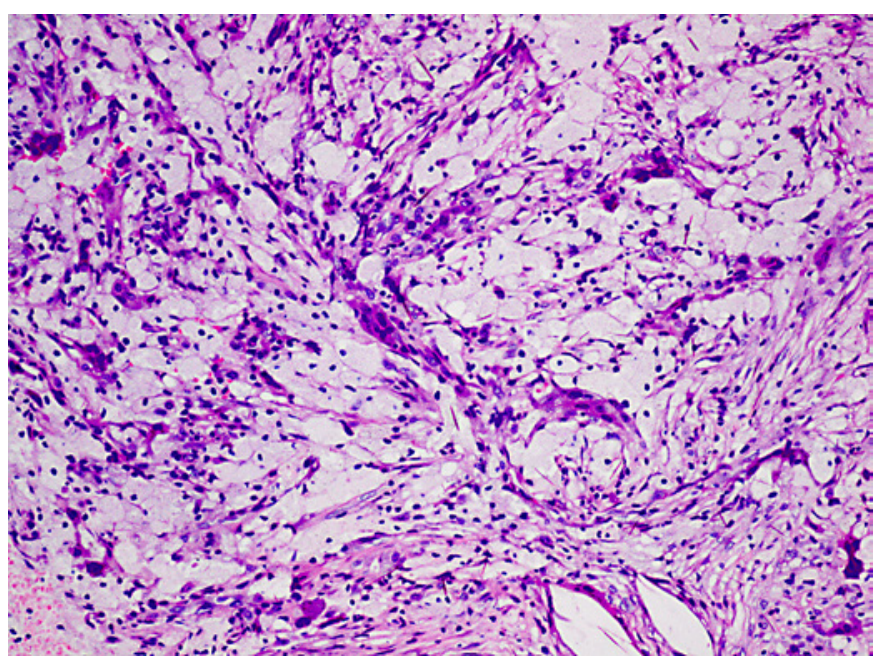

Fig. 3. Sheets of foamy histiocytes including multinucleated giant cells and cholesterol clefts present in the cellular areas of the sample.

or mycobacterial growth. Furthermore, blood investigations for infections through blood cultures, serology for Leishmania, Brucellosis, and tuberculosis were all normal.

Meanwhile, the patient restarted prednisolone because of gastrointestinal symptoms. Initially, this led to symp-

Xanthogranulomatous Osteomyelitis and Crohn's Disease

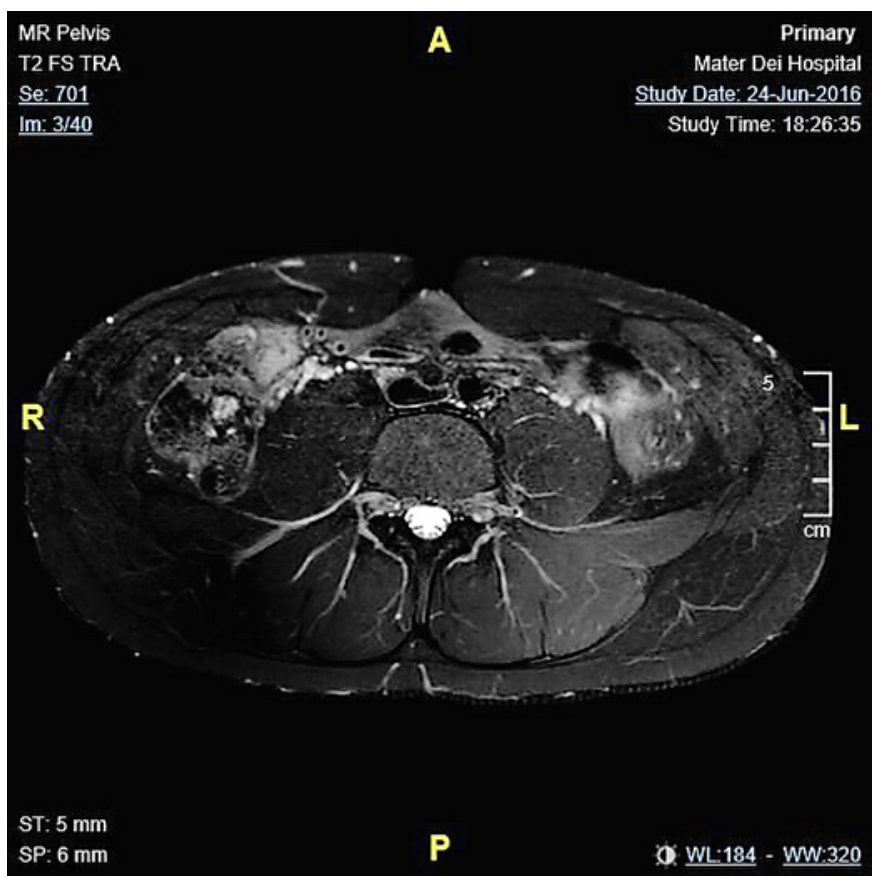

Fig. 2. Transverse T2-weighted MRI of the pelvis with fat saturation, showing the right pubic ramus lesion.

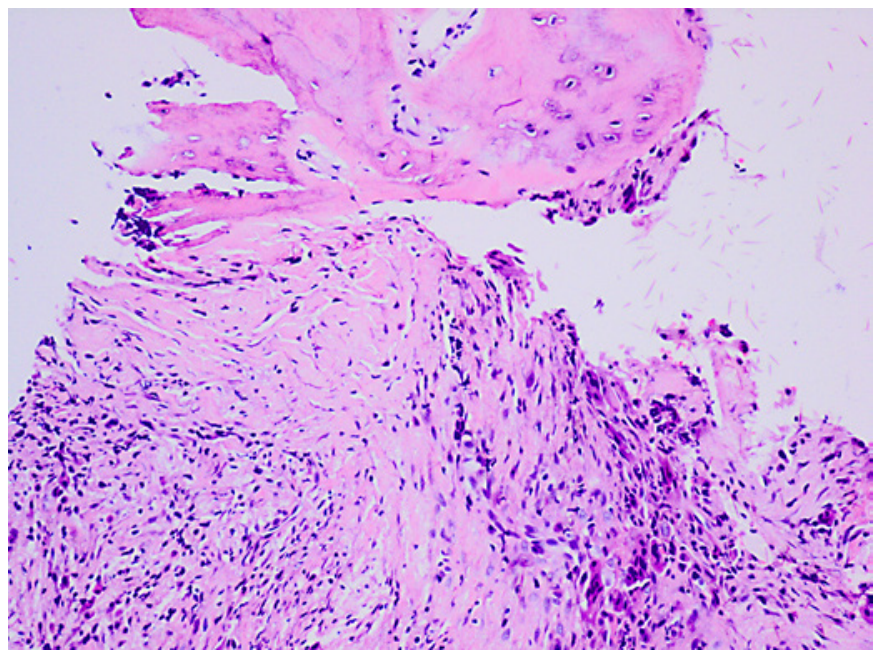

Fig. 4. The same granulomatous process with more prominent fibrosis infiltrating the bone.

tom resolution, but his symptoms recurred when prednisolone was reduced to $15 \mathrm{mg}$ daily. Thus, infliximab and azathioprine were initiated, and 3 months later, pelvic pain resolved completely. Follow-up of the pelvic lesion by MRI demonstrated a progressive size reduction, this being $27 \times 40 \mathrm{~mm}$ after 24 months of treatment.

GE Port J Gastroenterol 2020;27:62-64 
Extraintestinal manifestations in inflammatory bowel disease are seen in approximately $25-40 \%$ of the patients. Xanthogranulomatous inflammation in adults is a rare chronic inflammatory condition usually affecting the gallbladder, kidney, pancreas, genitalia, and salivary glands, with bones, brain, and lung rarely affected. Infiltration of macrophages and histiocytes occurs in the affected tissues. The histological features are characterized by sheets of foamy histiocytes. There is cytokine release that recruits additional immune cells, thus contributing to a potent immunological response. Delayed-type hypersensitivity reaction of cell-mediated immunity (CD4 and CD8) has been implicated in its pathogenesis [1]. Immune-related abnormalities might explain why both conditions responded to azathioprine and infliximab. Radiologically, it mimics a malignancy, which is one of the most serious differentials to be ruled out.

To date, about 16 cases have been described. In 3 patients, a pathogen was isolated from biopsy culture [1-3]. Antibiotics, drainage, curettage, and grafting were treatments used in other cases $[1,2,4,5]$.
To our knowledge, xanthogranulomatous inflammation was never reported involving bone in patients with inflammatory bowel disease. In cases of CD and bone pain, XO should be considered. Underlying bone infection should always be excluded. Both $\mathrm{CD}$ and XO are immune-mediated pathologies, as suggested by their response to immunosuppressive treatment. A collaborative effort between clinicians may help in shedding more light on whether there is a true association between them or whether this was only a co-incidence.

\section{Statement of Ethics}

The authors have no ethical conflicts to disclose.

\section{Disclosure Statement}

The authors have no conflicts of interest to declare.

References

1 Cheema A, Arkader A, Pawel B. Xanthogranulomatous osteomyelitis of the humerus in a pediatric patient with Alagille syndrome: a case report and literature review. Skeletal Radiol. 2017 Oct; 46(10):1447-52.

2 Borjian A, Rezaei F, Eshaghi MA, Shemshaki H. Xanthogranulomatous osteomyelitis. J Orthop Traumatol. 2012 Dec;13(4):217-20.

3 Kamat G, Gramapurohit V, Myageri A, Shet$\operatorname{tar}$ C. Xanthogranulomatous osteomyelitis presenting as swelling in right tibia. Case Rep Pathol. 2011;2011:257458.

4 Kaneuchi Y, Tajino T, Hakozaki M, Yamada $\mathrm{H}$, Tasaki K, Hasegawa O, et al. Xanthogranulomatous osteomyelitis of the distal tibia: a case report. Int J Rheum Dis. 2017 Dec;20(12): 2238-41.

5 Sapra R, Jain P, Gupta S, Kumar R. Multifocal bilateral xanthogranulomatous osteomyelitis. Indian J Orthop. 2015 Jul-Aug;49(4):482-4. 